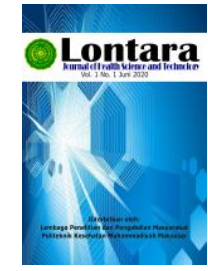

http://jurnal.poltekkesmu.online/lontarariset

Vol 2, No. 2, Desember 2021, pp 106-112

p-ISSN:0000-0000 dan e-ISSN: 2721-6179

DOI: https://doi.org/10.53861/lontarariset.v2i2

\title{
IDENTIFIKASI KARBON MONOKSIDA DALAM DARAH PADA PENJUAL BUAH DI JEMBATAN KEMBAR SUNGGUMINASA
}

\author{
Waode Rustiah, Andi Fatmawati, Ashrafiyah \\ Teknologi Laboratorium Medis, Politeknik Kesehatan Muhammadiyah Makassar \\ Email: waoderustiah79@gmail.com
}

\begin{tabular}{l}
\hline \multicolumn{1}{c}{ Artikel info } \\
\hline Artikel history: \\
Received; 03-09-2021 \\
Revised: 22-10-2021 \\
Accepted; 24-11-2021 \\
\hline
\end{tabular}

Keyword:

Blood, Carbon monoxide, Alkali Dilution Test Method

\section{Kata Kunci:}

Darah,

Karbonmonoksida, Metode Uji Alkali Dilusi

\begin{abstract}
The chemical compound of CO gas is a gas that has no color and contributes greatly to environmental pollution as a result of incomplete combustion of fuel produced from motor vehicles. Carbon monoxide is very dangerous (toxic, so it is often referred to as the "silent killer". The presence of CO gas will be very dangerous if inhaled by humans because the gas will replace the position of oxygen that binds to hemoglobin in the blood. The purpose of the study was to identify the presence or absence of carbon monoxide $(\mathrm{CO})$ in the blood of fruit sellers at the Sungguminasa Twin Bridge. This research is an analytical observational field research using the alkaline dilution test method. The sampling technique used purposive sampling with the criteria of working more than one year, working 8 hours a day and not smoking. The number of samples used as many as 9 samples of venous blood. From the results of this study, it can be concluded that the presence of carbon monoxide gas was not identified in all blood samples of fruit sellers at the Sungguminasa Twin Bridge. This is because in the alkaline dilution test method, CO gas can only be identified with saturation levels above $20 \%$.
\end{abstract}

Abstrak. Senyawa kimia gas CO adalah gas yang tidak memiliki warna dan berkonstribusi besar dalam pencemaran lingkungan akibat dari pembakaran tidak sempurna bahan bakar yang dihasilkan dari kendaraan bermotor. Karbon monoksida sangat berbahaya (beracun) sering disebut sebagai "silent killer". Keberadaan gas CO akan sangat berbahaya jika terhirup oleh manusia karena gas itu akan menggantikan posisi oksigen yang berikatan dengan hemoglobin dalam darah. Tujuan penelitian untuk mengidentifikasi ada atau tidaknya karbon monoksida (CO) dalam darah penjual buah di Jembatan Kembar Sungguminasa. Penelitian ini merupakan penelitian lapangan yang bersifat observasional analitik dengan menggunakan metode uji alkali dilusi. Teknik pengambilan sampel menggunakan purposive sampling dengan kriteria bekerja lebih dari satu tahun, sehari kerja 8 jam dan tidak merokok. Jumlah sampel yang digunakan sebanyak 9 sampel darah vena. Dari hasil penelitian ini dapat disimpulkan bahwa tidak teridentifikasi adanya gas karbon monoksida pada seluruh sampel darah penjual buah di Jembatan Kembar Sungguminasa. Hal ini karena dalam metode uji alkali dilusi, gas CO hanya mampu teridentifikasi dengan kadar saturasi diatas $20 \%$. 


\section{Coresponden author:}

Email: waoderustiah79@gmail.com

artikel dengan akses terbuka dibawah lisensi CC BY -4.0

\section{PENDAHULUAN}

Udara adalah campuran beberapa macam gas yang perbandingannya tidak tetap. Udara berperan penting dalam kehidupan makhluk hidup di bumi, salah satunya yang kita hirup untuk bernafas. Masuknya atau dimasukkannya zat, energi, dan komponen lain ke dalam udara karena kegiatan manusia yang menyebabkan mutu udara turun serta tidak memenuhi fungsinya seperti sebagaimana mestinya, yang demikian itu disebut pencemaran udara. Pencemaran udara merupakan masalah lingkungan global yang terjadi di seluruh belahan dunia (Pratiwi et all, 2018).

Pencemaran udara menurut Peraturan Pemerintah RI No. 41 Tahun 1999 adalah masuk atau dimasukkannya makhluk hidup, zat, energi dan komponen lain ke udara atau berubahnya tatanan udara oleh kegiatan manusia atau oleh proses alam, sehingga kualitas udara turun sampai ke tingkat tertentu menyebabkan udara menjadi kurang atau tidak sesuai dengan peruntukannya lagi. Pencemaran lingkungan sudah terjadi pula di lingkungan udara dengan segala dampak yang di timbulkan. Salah satu pemicu pencemaran udara adalah aktivitas kendaraan bermotor yang merupakan salah satu polutan utama yang dihasilkan oleh aktivitas pembakaran bahan bakar minyak kendaraan serta selalu berpindah pindah dari satu tempat ke tempat lain dan selama perjalanannya mengeluarkan hasil pembakaran yang tak sempurna seperti gas karbon monoksida (Muzayyid, 2014).

Senyawa kimia gas $\mathrm{CO}$ adalah gas tidak memiliki warna dan sebagai salah satu gas yang berkonstribusi besar dalam pencemaran lingkungan akibat dari pembakaran tidak sempurna bahan bakar yang dihasilkan dari kendaraan bermotor. Akibat yang dihasilkan dari pembakaran tersebut yakni senyawa kimia gas CO di udara tersebut menimbulkan beberapa gangguan kesehatan yang dapat dirasakan manusia seperti halnya menurunkan distribusi oksigen dalam darah manusia (Muzayyid, 2014).

Salah satu pekerjaan yang rentan terpapar gas karbonmonoksida adalah pedagang buah yang bertempat dipinggir jalan raya. Jalan raya merupakan banyak menghasilkan polusi udara akibat asap kendaraan bermotor yang berlalu lalang yang dapat merusak sistem pernapasan manusia. Menurut Arifin (2019) pengaruhnya terhadap tubuh manusia adalah akan bercampurnya gas karbonmonoksida (CO) dengan Hemoglobin $(\mathrm{Hb})$ dalam darah menjadi karboksihemoglobin ( $\mathrm{COHb}$ ). Penambahan jumlah karboksihemoglobin $(\mathrm{COHb})$ dalam darah dapat menyebabkan pengaliran oksigen dalam darah terhambat (Umami et al, 2018).

Berdasarkan penelitian yang sebelumnya oleh Muzayyid (2014) melakukan penelitian tentang "Studi Konsentrasi Kadar Karbon Monoksida (CO) Di Jalan A. Pettarani Kota Makassar 2014" 
menunjukkan hasil kadar gas CO tertinggi di lokasi IV sebesar 3173,65 $\mu \mathrm{g} / \mathrm{Nm} 3$ pada pagi hari, $2128,49 \mu \mathrm{g} / \mathrm{Nm} 3$ pada siang hari dan $3715,85 \mu \mathrm{g} / \mathrm{Nm} 3$ pada sore hari. Rata-rata kadar CO udara ambien di lokasi yaitu 3005,99 $\mu \mathrm{g} / \mathrm{Nm} 3$. Hal ini karena banyak kendaraan melintas pada Jalan A. Pettarani dapat berpengaruh terhadap meningkatnya kadar CO di udara, sehingga hasil pengukuran kadar CO di udara ambien pada titik tersebut tinggi.

Berdasarkan latar belakang masalah yang telah dikemukakan diatas, maka penulis melakukan penelitian dengan mengidentifikasi karbon monoksida (CO) dalam darah pada penjual buah di Jembatan Kembar Sungguminasa.

\section{BAHAN DAN METODE}

Jenis penelitian ini termasuk penelitian lapangan yang bersifat observasional laboratorik dengan lokasi penelitian di Laboratorium Toksikologi Klinik Poltekkes Muhammadiyah Makassar. Penelitian ini menggunakan teknik purposive sampling yang memenuhi kriteria inklusi, yaitu bekerja selama setahun, lama kerja maksimal 8 jam/hari dan tidak merokok.

Bahan yang digunakan adalah Sampel darah, larutan $\mathrm{NaOH} 10 \%$ dan aquades. Alat yang digunakan adalah Spuit $3 \mathrm{cc}$, jarum, holder, tabung EDTA, torniquet, swab alkohol, pipet tetes, tabung reaksi dan rak tabung.

Metode Pengambilan Sampel sebagai berikut: Disiapkan alat dan bahan. Memakai alat pelindung diri seperti masker dan handscoon. Lalu dipasang tourniquet pada lengan. Ditentukan vena yang akan ditusuk dan disterilkan dengan alcohol 70\%. Diarahkan pasien mengepal tangannya lalu dilakukan pengambilan darah dengan menusuk vena menggunakan jarum dengan sudut 15-30 derajat. Penghisap jarum ditarik perlahan hingga mencukupi volume darah yang dibutuhkan. Selanjutnya tourniquet dilepaskan. Lalu jarum ditarik keluar perlahan dengan memberikan kapas kering pada bagian yang telah ditusuk. Pasien diarahkan untuk menekan kapas tersebut lalu diberikan plester untuk menutupi bekas luka jarum (Umar, B. 2020). Setelah itu darah dimasukkan ke dalam tabung yang berisi antikoagulan lalu dihomogenkan dengan baik.

Prosedur Kerja Uji Alkali Dilusi adalah sebagai berikut: Tabung reaksi diisi masing-masing $10 \mathrm{ml}$ aquadest. kemudian ditambahkan 2 tetes darah sampel pada tabung reaksi pertama, dan 2 tetes darah sampel kontrol pada tabung kedua. Lalu ditambahkan 5 tetes $\mathrm{NaOH} 10 \%$ pada masing-masing tabung reaksi lalu dihomogenkan hingga darah kontrol berubah warna menjadi hijau kecoklatan (Linda, A.V, et al 2016).

Interpretasi Hasil adalah sebagai berikut: Darah normal akan segera berubah warna menjadi hijau kecoklatan ketika ditetesi $\mathrm{NaOH} 10 \%$ karena terbentuk hematin alkali. Sedangkan darah yang positif mengandung CO dengan kadar saturasi $20 \%$ tidak berubah warnanya dalam kurun waktu satu menit, dengan mempertahankan warna pertama (merah muda) tergantung pada konsentrasi CO karena bersifat lebih resisten terhadap pengaruh alkali. Kemudian setelah satu menit terjadi perubahan warna maka dinyatakan positif (Kunsah et al, 2019). 


\section{HASIL PENELITIAN}

Pada penelitian ini, sampel yang diambil sebanyak 9 sampel darah pada penjual buah yang berada di sekitaran Jembatan Kembar Sungguminasa. Data hasil uji kontrol dan hasil penelitian disajikan pada tabel 1 dan 2 .

Tabel 1. Uji Kontrol Karbonmonoksida

\begin{tabular}{lllll}
\hline No. & Kode Sampel & Hasil & Keterangan & \\
\hline & & Aquadest & NaOH $10 \%$ & \\
\hline 1. & Kontrol Positif $(+)$ & Merah muda & Merah muda & $(+)$ Positif CO \\
\hline 2. & Kontrol Negatif $(-)$ & Merah muda & Hijau kecoklatan & $(-)$ Negatif CO \\
\hline
\end{tabular}

(Sumber: Data Primer, 2021)

Tabel 2. Uji Hasil Analisis Kualitatif Karbonmonoksida

\begin{tabular}{lllll}
\hline No. & Kode Sampel & & Hasil & Keterangan \\
\hline & & Aquadest & NaOH 10\% & \\
\hline 1. & A & Merah muda & Hijau kecoklatan & $(-)$ Negatif CO \\
\hline 2. & B & Merah muda & Hijau kecoklatan & $(-)$ Negatif CO \\
\hline 3. & C & Merah muda & Hijau kecoklatan & $(-)$ Negatif CO \\
\hline 4. & D & Merah muda & Hijau kecoklatan & $(-)$ Negatif CO \\
\hline 5. & E & Merah muda & Hijau kecoklatan & $(-)$ Negatif CO \\
\hline 6. & F & Merah muda & Hijau kecoklatan & $(-)$ Negatif CO \\
\hline 7. & G & Merah muda & Hijau kecoklatan & $(-)$ Negatif CO \\
\hline 8. & H & Merah muda & Hijau kecoklatan & $(-)$ Negatif CO \\
\hline 9. & I & Merah muda & Hijau kecoklatan & $(-)$ Negatif CO \\
\hline (Sumber: Data Primer, 2021) & &
\end{tabular}

\section{PEMBAHASAN}

Penelitian ini dilakukan pada penjual buah di jembatan kembar Sungguminasa, dimana teknik pengambilan sampel yang digunakan adalah teknik purposive sampling dengan kriteria bekerja selama kurang lebih setahun, per hari kerja selama 8 jam dan tidak merokok. Hal ini karena menurut Mukono (2008) dalam Dewanti (2018) menyatakan bahwa asap rokok mengandung CO sekitar 400-457 ppm sehingga sangat berpengaruh terhadap hasil penelitian. Dari kriteria tersebut didapatkan 9 sampel darah penjual buah di Jembatan Kembar Sungguminasa.

Pengambilan sampel darah dari para responden, selanjutnya dimasukkan ke dalam tabung EDTA yang berisi antikoagulan. Pemilihan tabung EDTA oleh peneliti agar sampel tidak rusak dan mencegah proses pembekuan darah. Lalu sampel tersebut dimasukkan ke dalam coolbox yang berisi es batu. Setelah itu sampel dikirim ke Laboratorium Toksikologi untuk penelitian lebih lanjut.

Dalam penelitian ini, peneliti menggunakan metode uji alkali dilusi. Prinsip dasar alkali dilusi ketika $\mathrm{CO}$ berikatan dengan $\mathrm{Hb}$, maka terbentuk $\mathrm{COHb}$ yang resisten terhadap alkali, sehingga menghambat pembentukan hematin alkali dalam darah. Metode alkali dilusi menggunakan aquadest dan larutan $\mathrm{NaOH} 10 \%$ karena dapat menyerap gas $\mathrm{CO}$. Apabila sampel diteteskan larutan $\mathrm{NaOH} 10 \%$ maka sampel tetap mempertahankan warna merah muda dan dinyatakan positif mengandung karbon 
monoksida (CO). Apabila terjadi perubahan warna pada sampel menjadi hijau kecoklatan, maka dinyatakan negatif karbon monoksida (CO).

Berdasarkan hasil penelitian yang telah dilakukan, maka tidak satupun sampel yang teridentifikasi adanya gas karbon monoksida (CO) pada darah penjual buah di Jembatan Kembar Sungguminasa ditandai dengan terjadinya perubahan warna hjiau kecoklatan pada sampel saat penambahan $\mathrm{NaOH} 10 \%$.

Beberapa faktor yang dapat mempengaruhi hasil dari penelitian ini disebabkan kadar CO pada responden masih dalam kategori rendah di dalam darah. Menurut Pratiwi et al, 2018 besar kecilnya kadar CO bisa disebabkan oleh faktor lain yang tidak diteliti, misalnya aktivitas luar rumah yang dilakukan oleh responden seperti berolahraga secukupnya, menghirup udara segar setelah berada di area yang rentan terpapar gas karbon monoksida (CO), mengkonsumsi buah dan sayur dan mempunyai sistem pertahanan tubuh atau imunitas yang kuat. Mengingat pula dua tahun terakhir dalam kondisi COVID-19 dimana ditetapkannya protokol kesehatan dengan lock down beberapa bulan yang mengharuskan masyarakat bekerja dari rumah sehingga kendaraan yang melintas di jalan raya berkurang. Hal ini bisa membuat kadar karbonmonoksida di udara menurun. Pemerintah juga mewajibkan memakai masker pasca lock down yang mampu mengurangi resiko masuknya gas karbon monoksida di dalam darah.

Dalam metode uji alkali dilusi, gas CO hanya mampu teridentifikasi dengan kadar saturasi diatas 20\%. Kadar saturasi adalah tolak ukur kesehatan untuk menakar besarnya kadar karbon monoksida dalam aliran darah. Jadi tidak menutup kemungkinan tidak terdapat gas CO dalam darah pada sampel yang diteliti. Secara umum, terdapat kadar CO dalam darah manusia dari hasil produk normal proses pemecahan sel tubuh atau hasil metabolisme. Menurut Isnaini, 2012 harga normal karbon monoksida dalam darah ada sekitar 0,5\%. Namun kadar tersebut bisa meningkat karena disebabkan faktor dari luar, salah satunya apabila terpapar gas karbon monoksida dari asap kendaraan bermotor dalam jumlah yang cukup banyak dan melewati batas normal yang ditetapkan.

Kadar CO dengan tingkat saturasi dibawah 20\% menurut WHO hal tersebut tidak berbahaya bagi tubuh dan belum menimbulkan dampak gejala apapun. Hal ini juga berdasarkan pada penelitian sebelumnya oleh Dewanti, 2018 menurut Hanniwati (1992) pada kadar COHb < 15\% belum terdapat gejala atau keluhan kesehatan. Juga pada penelitian yang dilakukan oleh Tasniim, 2014 di mana kadar $\mathrm{COHb}<15 \%$ tidak terdapat hubungan dengan keluhan kesehatan. Menurut Fardiaz, 2010 faktor penting yang menentukan pengaruh $\mathrm{CO}$ terhadap tubuh adalah konsentrasi kadar $\mathrm{HbCO}$ dalam darah, dimana semakin tinggi presentasi hemoglobin yang terikat oleh $\mathrm{CO}$ dalam bentuk HbCO, maka semakin berpengaruh terhadap kesehatan manusia.

Berdasarkan dari hasil wawancara, rata-rata penjual buah di Jembatan Kembar Sungguminasa bekerja selama kurang lebih 24 jam dalam sehari dan telah bekerja selama 2-4 tahun lamanya. Dalam setahun dan bekerja selama 24 jam/hari paparan gas karbon monoksida sangat rentan terhirup dan masuk bersama aliran darah. Menurut ACGIH TLV-TWV batas keterpaparan maksimum adalah 25 
ppm untuk waktu 8 jam. Menurut Laporan Utama Informasi Kinerja Pengelolaan Lingkungan Hidup Pemerintah Daerah Kabupaten Gowa Tahun 2019 menunjukkan dari hasil pemantauan di beberapa titik di Kabupaten Gowa didapatkan kualitas udara dengan kadar CO tertinggi ditemukan pada area jalanan yang dilewati oleh truk-truk pengangkut galian tambang di Daerah Kelurahan Mawang Kecamatan Somba Opu tetapi masih dalam tingkat yang belum melewati baku mutu. Namun pada titik tertentu dan pada jam padat lalu lintas kadar karbon monoksida sudah sangat tinggi dan melewati baku mutu (Pemkab Gowa, 2019).

Apabila kadar melewati batas baku mutu yang ada, kadar tersebut dapat menurunkan kesehatan manusia dan lingkungan karena sifatnya yang toksik atau beracun. Keracunan gas CO dapat ditandai dengan gejala ringan hingga berat berupa pusing/sakit kepala, rasa tidak enak pada mata hingga kematian. Untuk mencegah dan mengurangi resiko masuknya gas karbon monoksida kedalam darah, dilakukan upaya menggunakan alat pelindung diri seperti masker dan berolahraga secukupnya (Khumeira dan Juliarnita, 2017).

\section{KESIMPULAN DAN SARAN}

Pada penelitian ini disimpulkan bahwa tidak teridentifikasi adanya gas karbon monoksida (CO) pada seluruh sampel darah penjual buah di Jembatan Kembar Sungguminasa. Adapun untuk peneliti selanjutnya disarankan menganalisis kadar $\mathrm{HbCO}$ dalam darah dengan menggunakan metode pemeriksaan yang lebih efektif dan akurat.

\section{UCAPAN TERIMA KASIH}

Penelitian ini dibiayai oleh Politeknik Kesehatan Muhammadiyah Makassar tahun 2021. Ucapan terima kasih yang luar biasa untuk semua pihak yang sudah banyak membantu penelitian ini hingga dapat terlaksana dengan baik.

\section{DAFTAR PUSTAKA}

Dewanti, I. R. 2018. Identifikasi Paparan CO, Kebiasaan dan Kadar COHb Dalam Darah Serta Keluhan Kesehatan di Basement Apartement Waterplace, Surabaya. Jurnal Kesehatan Lingkungan, 10(1), 59-69.

Drilna, P.U. 2016. Hubungan Kadar Karboksihemoglobin (COHb) Dalam Darah Dengan Kelelahan Kerja Pada Pekerja Bengkel Kendaraan Bermotor Di Kota Pontianak. Naskah Publikasi.

Fardiaz, S. 2010. Polusi Air dan Udara. Yogyakarta, Kanisius.

Isnaini, W. L. 2012. Pengaruh Paparan Gas Karbon Monoksida (CO) terhadap Kelelahan Kerja pada Pedagang Asongan di Terminal Tirtonadi Surakarta. Skripsi. Surakarta: Fakultas Kedokteran Universitas Sebelas Maret.

Khumeira dan Juliarnita, G.D. 2017. Laporan Praktikum Laboratorium Lingkungan 2. Jurnal Teknik Lingkungan. Universitas Trisakti. 
Kunsah, B et al. 2019. Modul Praktikum Toksikologi Klinik. Laboratorium Kimia Kesehatan Fakultas Ilmu Kesehatan Universitas Muhammadiyah Surabaya.

Linda, A.V, et al. 2016. Uji Alkali Delution. Makalah. Manado: Fakultas Kedokteran Universitas Sam Ratulangi.

Muzayyid, M. (2014). Analisis Distribusi Kadar Karbon Monoksida (CO) di Jalan A. Pettarani Kota Makassar Tahun 2014 (Doctoral dissertation, Universitas Islam Negeri Alauddin Makassar).

Noor, F.S. 2009. Perbandingan Uji Alkali Dilusi Dengan Uji Formalin Pada Darah Tikus Wistar Setelah Terpapar Asap Knalpot Dengan Kadar CO 1800 PPM Selama 4 Jam. KTI. Semarang: Fakultas Kedokteran Universitas Diponegoro.

PARAMAHITA, A. (2018). Gambaran Kadar Hemoglobin Pada Ojek Motor Online (Go-Jek) Di Kantor Go-Jek Teuku Umar Barat Denpasar (Doctoral dissertation, Jurusan Analis Kesehatan).

Pemerintah Kabupaten Gowa. 2019. Laporan Utama Dokumentasi Informasi Kinerja Pengelolaan Dinas Lingkungan Hidup: Sulawesi Selatan, Gowa.

Pratama dan Aditya, D.M. 2017. Perbedaan Jumlah Eritrosit Menggunakan Antikoagulan K2EDTA DAN K3EDTA. Skripsi. D4 Analis Kesehatan Universitas Muhammadiyah Semarang.

Khumeira dan Juliarnita, G.D. 2017. Laporan Praktikum Laboratorium Lingkungan 2. Jurnal Teknik Lingkungan. Universitas Trisakti

Pratiwi, D.R et al. 2018. Gambaran Kadar HbCO Dalam Darah Pada Masyarakat Dusun Demeling, Gedangan, Sidoarjo. Gema Kesehatan Lingkungan,16,60-61.

Rahma, S. N. Hubungan Paparan Gas CO (Karbonmonoksida) di Udara Dengan Kadar COHb Darah Petugas Parkir Basement di Mall Surabaya. Jurnal Kesehatan Lingkungan,11,226.

Susilowati, I. T. 2021. Analisa Kadar Karboksihemogloboin (HbCO) Pada Driver Ojek Online (Gojek) dan Petugas Sukarelawan Pengatur Lalu Lintas Di Surakarta. Jurnal Kesehatan Kusuma Husada. 